\title{
Theoretical studies of the global minima and polarizabilities of small lithium clusters
}

\author{
Han-Shi Hu, ${ }^{1}$ Ya-Fan Zhao, ${ }^{2}$ Jeff R. Hammond, ${ }^{3}$ Eric J. Bylaska, ${ }^{1}$ Edoardo Aprà, ${ }^{1}$ \\ Hubertus J. J. van Dam, ${ }^{1}$ Jun Li, ${ }^{1,2}$ Niranjan Govind, ${ }^{1 *}$ Karol Kowalski ${ }^{1 *}$ \\ ${ }^{1}$ William R. Wiley Environmental Molecular Sciences Laboratory, Pacific Northwest National \\ Laboratory, Richland, Washington 99352, USA \\ ${ }^{2}$ Department of Chemistry \& Key Laboratory of Organic Optoelectronics and Molecular \\ Engineering of Ministry of Education, Tsinghua University, Beijing 100084, China \\ ${ }^{3}$ Parallel Computing Lab, Intel Corporation, Santa Clara, California 95054-1549, USA \\ *Corresponding authors email: niri.govind@pnnl.gov, karol.kowalski@pnnl.gov
}

\begin{abstract}
Lithium clusters $\operatorname{Li}_{n}(n=1-20)$ have been investigated with density functional theory (DFT) and coupled-cluster (CC) methods. The global minima are located via an improved basin-hopping algorithm. Simulated polarizabilities are in good agreement with the measured data generally. The simulated polarizabilities for $\mathrm{Li}_{6}, \mathrm{Li}_{12}$ and $\mathrm{Li}_{19}$ are in reasonable agreement when thermal effects are included. except the $\mathrm{Li}_{3}$ cluster. A linear correlation for the inverse relationship between the CCSD calculated polarizabilities and ionization potential (IP) has been reported to have the linear coefficient of 0.996 , which further strengthens our simulations.
\end{abstract}

\section{Introduction}

Lithium, with only three electrons and one delocalized electron in the valence shell, is the lightest metallic element and is a good starting point for theoretical studies of light alkali metals and their spectroscopic properties [1]. Furthermore, there is continued interest in atomic clusters since they are the smallest condensed matter systems and their physical and chemical properties are known to be sensitive to system size [2]. Lithium clusters, $\mathrm{Li}_{n}$, have been studied extensively both 
experimentally and theoretically in terms of their properties, making them ideal systems for further investigations [3]. Experimental measurements for lithium clusters include isotropic polarizability [4], ionization potentials (IPs) [5], electron affinities (EAs) [6] and cohesive energies [7]. Meanwhile, theoretical investigations have reported results using DFT and ab initio wave function approaches, including geometrical and electronic structures [8], spectroscopic parameters [9], and bonding analyses $[6,10]$. Despite these numerous theoretical studies, there are still discrepancies, such as the geometrical structures of the reported global minima of the various clusters [8]. For example, with the $\mathrm{Li}_{20}$ cluster, both structures with $\mathrm{C}_{1}$ [11] and $T_{d}$ [12] symmetries have been reported as stable structures and the calculated polarizability for $\mathrm{T}_{\mathrm{d}}$ structure is around $446.3 \pm 120.0$ a.u. higher than the experimental result [12].

One solution to this dilemma is to compare the computational results with experimentally measured spectra $[5,13]$ and assign the structures of the isomers accordingly. This approach, although reasonable, has its limitations since it requires highly accurate calculations [14]. Besides, both thermal and quantum fluctuations [15] do play an important role in determining the properties of lithium clusters [9]. For the clusters with sufficiently flat potential landscapes, there are several local minima that can co-exist on the time scale of experiment, which makes the measured spectrum challenging to interpret [6]. In addition, with light mass nuclei, quantum fluctuations such as zero-point motion and tunneling effects are also non-negligible.

In this paper, we report a systematic study of simulated polarizabilities of small lithium clusters based on DFT and CC singles and doubles (CCSD) [16] levels of theory, with global-minimum structures obtained using an improved basin-hopping procedure. We compare our calculations with experimentally measured polarizabilities [4] up to the $\mathrm{Li}_{20}$ cluster. We find that the CCSD results are closest to the experimental ones, while the DFT results, with different exchange-correlation functionals, are consistent with each other and in overall good agreement with CCSD. 
Energies of $\mathrm{Li}_{n}$ isomers are also compared at the $\operatorname{CCSD}(\mathrm{T})$ level of theory [17] to account for the triples contributions. . Thermal fluctuation effects are also discussed for the $\mathrm{Li}_{6}, \mathrm{Li}_{12}$ and $\mathrm{Li}_{19}$ clusters to understand the discrepancy between simulated polarizabilities and measured values. $\mathrm{Li}_{3}$ is a particularly challenging case, where the calculated polarizability is 319.20 a.u., a lot higher compared with the measured value of $232.82 \pm 23$ a.u.. To further strengthen our calculated polarizability based on both DFT and CCSD levels of theory, we have also investigated the inverse relationship between the CCSD calculated polarizabilities and ionization potentials (IP) and find a linear correlation of 0.996 for all the clusters except for $\mathrm{Li}_{3}$. This suggests that the experimental measured polarizability for this system may need to be revisited.

\section{Theory and Computational details}

\subsection{Theory}

Over the years there have been investigations of the polarizabilities of small lithium clusters using DFT based linear response approaches [18]. Here, for the first time, we report extensive linear-response CCSD calculations for the $\mathrm{Li}_{10-20}$ clusters and CCSDT calculations for the $\mathrm{Li}_{1-4}$ clusters.

\section{(1) Analytic Derivatives of the CC Energy}

Within the framework of linear-response CC (LR-CC theory) [19], the modified energy functional that satisfies the generalized Hellmann-Feynman theorem is written as

$$
\begin{aligned}
& E=\tilde{E}=\left\langle\Phi\left|(1+\Lambda) e^{-T} H e^{T}\right| \Phi\right\rangle \\
& \Lambda=\Lambda_{1}+\Lambda_{2} \\
& \Lambda_{m}=\frac{1}{(m !)^{2}} \sum_{i_{1, \ldots, i}} \sum_{a_{1, \ldots, a_{m}}} \lambda_{i_{1} \ldots i_{m}}^{a_{1} \ldots a_{m}} X_{a_{1}} \ldots X_{a_{m}} X_{i_{1}}^{+} \ldots X_{i_{m}}^{+} \quad(\mathrm{m}=1,2)
\end{aligned}
$$

where $\lambda_{i_{1} \ldots i_{m}}^{a_{1} \ldots a_{m}}$ are Lagrange multipliers that define de-excitation operator $\Lambda$. The second derivative of the energy, which corresponds to the polarizability, is represented as

$$
\frac{d^{2} \tilde{E}}{d x d y}=
$$


$\left\langle\Phi\left|(1+\Lambda) e^{-T} \frac{\partial^{2} H}{\partial x \partial y} e^{T}\right| \Phi\right\rangle+$

$\hat{P}(x, y)\left\langle\Phi\left|(1+\Lambda) e^{-T}\left[\frac{\partial H}{\partial y}, \frac{\partial T}{\partial x}\right] e^{T}\right| \Phi\right\rangle+\left\langle\Phi\left|(1+\Lambda) e^{-T}\left[\left[\frac{\partial H}{\partial y}, \frac{\partial T}{\partial y}\right], \frac{\partial T}{\partial x}\right] e^{T}\right| \Phi\right\rangle$

where $\hat{P}(x, y)$ is the symmetric permutation operator with $\hat{P}(x, y) f(x, y)=$ $f(x, y)+f(y, x)$. The derivatives of cluster operator $T$ are calculated from the first-order CC response equations

$\left\langle\Phi_{i}^{a}\right|\left(e^{-T} \frac{\partial H}{\partial x} e^{T}+\left[e^{-T} H e^{T}, \frac{\partial T}{\partial x}\right]|\Phi\rangle=0\right.$

$\left\langle\Phi_{i j}^{a b}\right|\left(e^{-T} \frac{\partial H}{\partial x} e^{T}+\left[e^{-T} H e^{T}, \frac{\partial T}{\partial x}\right]|\Phi\rangle=0\right.$

(6)

The above equations form a linear system of equations for derivatives of singly and doubly excited cluster amplitudes. We refer the reader to more comprehensive reviews for details [20].

\section{(2) Global-Minimum Search Algorithm}

In order to explore the impact of the cluster geometries on the calculated polarizabilities, we used an improved global minimum structure search approach based on the basin hopping algorithm [21] by local minimizations using DFT calculations as implemented in the TGmin program [22].

To improve the efficiency of the global minimum search, the approach also includes a comparison function for structure similarity based on the ultrafast shape recognition (USR) algorithm [23] to eliminate duplicate structures and to avoid local minima trapping during the global minimum search. A more controllable displacement function is implemented so under coordinated atoms have a higher probability to be displaced. The displaced structures are adjusted by a relaxation function based on the covalent radii of elements [24], so as to avoid atoms being to close to each other. By calling the batch system on the computing platform, numerous standalone local minimization calculations can be run simultaneously, 
thereby improving the efficiency of the search and reducing the overall computational effort.

\subsection{Computational Details}

The initial global minimum structures searches were performed with the TGMin program, described earlier, in conjunction with the PBE [25] exchange-correlation (XC) functional and the DZP [26] basis set (1s orbital being frozen). Structures from the global minimum search were further optimized using DFT with the B3LYP XC functional [27] and the cc-pVTZ [28] basis set. The local minimum structures are further confirmed by vibrational frequency calculations. These and all DFT and CC based polarizabiity [29] calculations were performed using all- electron Gaussian basis set calculations with the NWChem 6.5 program [30]. Polarizability calculations were performed at the CCSD level of theory and several DFT exchange-correlation functionals (BLYP [31], B3LYP, BHLYP [31,32], CAM-B3LYP [33]). The POL1 [34] basis set was used for all polarizability calculations except for cases where convergence issues were encountered and the cc-pVTZ basis was used. Several isomers were compared using the CCSD, DFT and CCSD(T)/POL1 single-point energies, respectively. Ionization potential (IP) calculations were also performed at the CCSD level of theory with the POL1 basis set. For the even, closed shell clusters, we have applied EOM-CCSD theory [35] to obtain the vertical IP energies (Table 6) for comparison.

\section{Results and Discussion}

As shown in Figs. 1\&2, the geometries of $\mathrm{Li}_{n}$ clusters are found to be planar up to $\mathrm{Li}_{5}$ ( $\mathrm{Li}_{1}$ and $\mathrm{Li}_{2}$ are not shown). Several isomers are discussed where there is a debate in the literature. Furthermore, the global minima are further confirmed by their simulated polarizabilities and the results are listed in Fig. 3 and Table 1 for comparison. All Li $i_{n}$ clusters have doublet multiplicity for $n$ with odd values and singlet for $n$ with even values unless mentioned specifically in Table S2. Our results show that both DFT and CCSD give reasonably close polarizability values compared with experiment. All five DFT-based simulated results are very similar to each other with 
standard deviations within 91-97 a. u., and CCSD gives the closest results to the measured one with a standard deviation of 74 a. u.. Simulated thermal effects at room temperature were also performed for $\mathrm{Li}_{6}, \mathrm{Li}_{12}$ and $\mathrm{Li}_{19}$ clusters to shed light on polarizability discrepancies between calculations and experiment (Table 5).

\subsection{Geometries and Polarizabilities of $\mathbf{L i}_{n}$}

$\mathbf{L i}_{3}$ - There have already been many discussions about the $\mathrm{Li}_{3}$ isomers including the pseudo-rotation barrier and dynamic effect for the Jahn-Teller distortion from $\mathrm{D}_{3 \mathrm{~h}}$ to either $a$ (vertex angle $>60^{\circ}$ ) or $b$ (vertex angle $<60^{\circ}$ ) $\mathrm{C}_{2 \mathrm{v}}$ structures, vibronic energies, electron spin resonance, and electronic structures [36], etc. Fig. 4(a) shows its potential energy surface, where there are two local minima corresponding to $a$ and $b$ structures, respectively. The pseudo-rotation effect has not been considered in this report. Instead, the surface scan of CCSD calculated polarizability is shown in Fig. 4(b), which shows that most of the calculated values are well above 300.0 a.u., much higher than the measured result of $232.82 \pm 23$ a.u. (Figs. 3(a) \& 3(b)). This large discrepancy suggests that even considering the pseudo-rotation effect may not help resolve its problem. Therefore, we have tried other analyses to further understand the discrepancy. Firstly, we have investigated various basis sets for these two geometries of $\mathrm{Li}_{3}$ as shown in Table 3. It shows that there are no significant basis-set effects that would narrow the CCSD and experimental gap. For example, the differences between aug-cc-pVDZ and aug-cc-pVQZ CCSD polarizabilities do not exceed 3 a.u.. Secondly, we have further performed the CCSDT/POL1 (Table 4) simulation on the polarizability of $\mathrm{Li}_{3}$ and the result is almost the same as the CCSD one (Table 1). Consequently, this confirms that high-order correlation effects does not account for the polarizability discrepancy of $\mathrm{Li}_{3}$. Thirdly, we have also investigated the inverse relationship (equation (7)) [37], where I represents ionization potential, $N$ for number of electrons, $Z$ for nuclear charge between the CCSD calculated polarizability and ionization potential (IP) of the lithium cluster $\mathrm{Li}_{n}$. Its corresponding linear correlation coefficient is 0.996 as shown in Fig. 4(c) [38]. The measured one, on the other hand, as represented by the red spot in Fig. 4(c), is below the linear fitted line. This again helps confirm, to some extent, our calculated results. 
(7)

Furthermore, we have investigated the impact of spin multiplicity on $\mathrm{Li}_{3}$ and its cation $\mathrm{Li}_{3}{ }^{+}$as well, since it is said that the multiplicity has effects for the polarizations of molecules (Table S2) [39]. As shown in Table S2, both molecules prefer the lower multiplicity states energetically. The $\mathrm{Li}_{3}$ isomer with ${ }^{4} A_{2}^{\prime}$ state has a larger polarizability (>60.0 a.u.) than the other two isomers with ${ }^{2} A_{1}$ and ${ }^{2} B_{2}$ states respectively. Same trend for $\mathrm{Li}_{3}{ }^{+}$, higher multiplicity states of ${ }^{3} \mathrm{~A}_{1}$ and ${ }^{3} \Sigma_{u}^{+}$have larger polarizabilities than that of ${ }^{1} A_{1}^{\prime}$. This phenomenon is due to the more dispersive of the higher orbitals occupied in the higher-multiplicity state ${ }^{4} A_{2}^{\prime}$ for $\mathrm{Li}_{3}$ and ${ }^{3} \mathrm{~A}_{1},{ }^{3} \mathrm{~S}_{u}^{+}$for $\mathrm{Li}_{3}{ }^{+}$.

$\mathbf{L i}_{4}, \mathbf{L i}_{5}$ - The global-minima structures of $\mathrm{Li}_{4}$ and $\mathrm{Li}_{5}$ as shown in Fig. 1, are planar lithium clusters. All larger lithium clusters $\left(\mathrm{Li}_{n}, \mathrm{n} \geq 6\right)$ are non-planar ones. On the other hand, there is a fairly stable no-pair bonding state for the $\mathrm{T}_{\mathrm{d}}$ symmetrized $\mathrm{Li}_{4}$ with electronic state of ${ }^{5} A_{2}$ and having all the four valence electrons unpaired [39].

$\mathbf{L i}_{6}$ - There is ample literature discussing the isomers of $\mathrm{Li}_{6}$ cluster and having different conclusions for the most stable one [40]. For example, the $\mathrm{C}_{5 \mathrm{v}}$ isomer, which is considered as the lowest isomer in a very recent work [41], is less energetically favorable than the $\mathrm{D}_{4 \mathrm{~h}}$ one based on our calculations with B3LYP, CCSD, and $\operatorname{CCSD}(\mathrm{T})$ methods. The $\operatorname{CCSD}(\mathrm{T})$ energy of the $\mathrm{C}_{5 \mathrm{v}}$ cluster is located 6.56 $\mathrm{kcal} / \mathrm{mol}$ above the $\mathrm{D}_{4 \mathrm{~h}}$ one which includes four twisted tetrahedral building blocks (Table 2 \& Fig. 1). The $\mathrm{C}_{2 \mathrm{v}}$ structure has also been investigated and its optimized geometry changes to $\mathrm{D}_{4 \mathrm{~h}}$ symmetry, which is the most stable one in this report. Meanwhile, it shows that $\operatorname{CCSD}(\mathrm{T})$ results change the order of $\mathrm{C}_{5 \mathrm{v}}$ and $\mathrm{D}_{3 \mathrm{~h}}$ compared with the CCSD ones, consistent with several previously reported data [42], which illustrates the importance of correlation effects due to the triple excitations in determining the relative energies of the $\mathrm{Li}_{6}$ clusters. Herein the $\mathrm{D}_{3 \mathrm{~h}}$ planar structure 
is the same as that found for $\mathrm{Au}_{6}$ [43]. Furthermore, the CCSD simulated polarizability of the most stable $\mathrm{D}_{4 \mathrm{~h}}$ isomer is also closest to the measured value among the three isomers (Table 2) [42]. However, even for the $\mathrm{D}_{4 \mathrm{~h}}$ isomer one can observe a significant difference between the CCSD and experimental polarizabilities (amounting to 94 a.u.). Table 1 also demonstrates a general trend in the calculated BLYP, B3LYP, BHLYP, CAM-B3LYP, and CCSD polarizabilities, which are significantly above the experimental data, as shown in Fig. 1 too. The zero-point corrected free energies based on B3LYP are further investigated and the free-energy gap $\Delta \mathrm{G}_{\text {zero }}$ does not change the energetic order of these three isomers, but make them closer to each other as shown in Table 2.

$\mathbf{L i}_{7}$ - Its global-minimum structure has a pentagonal bipyramid structure with $\mathrm{D}_{5 \mathrm{~h}}$ symmetry, which is the same as former reports [41]. It is interesting to note that this structure becomes the basic building blocks for larger lithium clusters (Fig. 1).

$\mathbf{L i}_{8}$ - The two isomers of $\mathrm{Li}_{8}$ shown in Fig. 1 are relatively close in energy. Although the $\mathrm{C}_{1}$ isomer has closer polarizability to the experimental result, the $\mathrm{T}_{\mathrm{d}}$ isomer is $0.45 \mathrm{kcal} / \mathrm{mol}$ more stable based on the $\operatorname{CCSD}(\mathrm{T})$ energies. The latter contains four tetrahedral building blocks while the $\mathrm{C}_{1}$ isomer can be viewed as combinations of two planar rhomboidal subgroups (Table 2). It is interesting to note that $\operatorname{CCSD}(\mathrm{T})$ decreases the energy gap between these two isomers. Besides, the result of $\Delta \mathrm{G}_{\text {zero }}$ changes the order of these two isomers. Comparing all the methods here, the CAM-B3LYP calculated polarizability yields the best agreement with the experimental data (Table 1).

Li $\mathbf{i}_{9}$ - The lowest energy isomer of Lig has $C_{1}$ symmetry, which is close to the $C_{4 v}$ one, as shown in Fig. 1. This structure includes eight tetrahedral subgroups, which is around $3.16 \mathrm{kcal} / \mathrm{mol}$ more stable than the $\mathrm{C}_{2 \mathrm{v}}$ one according to the $\operatorname{CCSD}(\mathrm{T})$ energies. The result of $\Delta \mathrm{G}_{\text {zero }}$ gives the same order. Furthermore, the polarizability of $\mathrm{C}_{1}$ (close to $\mathrm{C}_{4 \mathrm{v}}$ ) isomer is almost 85 a.u. closer to the experimental result than that of $\mathrm{C}_{2 \mathrm{v}}$ (Table 2), which further confirms the global minimum of Lig cluster. 
$\mathbf{L i}_{10}$ - Here two isomers of $\mathrm{Li}_{10}$ are lower in energy, with the $\mathrm{D}_{2 \mathrm{~d}}$ structure being the lowest energy one, as confirmed by both B3LYP and CCSD(T) energies (Table 2). Although the $\mathrm{C}_{4 \mathrm{v}}$ isomer has a closer polarizability to the measured one, both of them are close to each other with a small gap of around 10 a.u. (Table 2). The result of $\Delta \mathrm{G}_{\mathrm{zero}}$ gives the same order showing that the $\mathrm{D}_{2 \mathrm{~d}}$ structure is more stable.

$\mathbf{L i}_{11-20}$ - The geometries of the local-minima structures of lithium clusters $\mathrm{Li}_{11-20}$ are shown in Fig. 2 and their simulated polarizabilities are listed in Table 1, accompanied by the experimental results for comparison. The match is quite good, except for two clusters $\mathrm{Li}_{12}$ and $\mathrm{Li}_{19}$, where the measured polarizabilities are more than one $\left(\mathrm{Li}_{12}\right)$ or two $\left(\mathrm{Li}_{19}\right)$ hundred higher than the calculated results (Table 1 and Fig. 3). For the $\mathrm{Li}_{19}$ cluster, the discrepancy is 245.51 a.u. without the inclusion of experimental errors that are in the range of $\sim 10 \%$ mainly caused by the velocity measurement. On the other hand, for $\mathrm{Li}_{20}$ cluster, our calculated value is very close to the measured one with a gap of only 40 a.u., while previously published works have found either one hundred lower [44] or four hundred higher [12] than the measured data.

Furthermore, for $\mathrm{Li}_{20}$, previously published work [12] report a simulated polarizability of 1667.3 a.u. and our calculated result is 1241.7 a.u., much closer to the measured result of 1201.2 a.u. These results show the accuracy of our algorithm for locating the global-minimum structure of the $\mathrm{Li}_{20}$ cluster. Unlike the $\mathrm{Au}_{20}$ cluster [45], with a global-minimum structure of $\mathrm{T}_{\mathrm{d}}$ symmetry, the global-minimum structure of $\mathrm{Li}_{20}$ is of $\mathrm{C}_{1}$ symmetry. It is worth noting that the $\mathrm{Li}_{n}$ clusters prefer 3D structures instead of planar geometries, very different from $\mathrm{Au}_{n}$ clusters. Clearly, even though the valence electrons of $\mathrm{Li}$ and $\mathrm{Au}$ are both s-shell electrons, the crucial difference is in the s-d hybridization, due to direct and indirect relativistic effects, in the latter. 


\subsection{Thermal Effects}

To investigate the thermal fluctuation effects on the structures of the $\mathrm{Li}_{6}, \mathrm{Li}_{12}$ and $\mathrm{Li}_{19}$ clusters, Gaussian basis set ab initio molecular dynamics (AIMD) simulations were performed on the optimum $\mathrm{Li}_{6}, \mathrm{Li}_{12}$ and $\mathrm{Li}_{19}$ clusters to sample the minima, respectively. These simulations were performed with the 6-31G* basis [46] and B3LYP exchange-correlation functional at 300K. The velocity-Verlet algorithm [47] was used to propagate nuclei and the temperature was controlled via the stochastic velocity-rescaling thermostat of Bussi, Donadio, and Parrinello [48] which correctly samples the canonical ensemble and minimally impacts dynamic properties. Structures were collected from short (1 ps) and long trajectories ( $10 \mathrm{ps})$, from which 50 random snapshots were extracted for the subsequent polarizability calculations. The AIMD calculations were performed with a development version of NWChem [49].

Statistical analyses of these calculations are given in Table 5. The averaged polarizabilities $\langle\alpha\rangle$ of these randomly selected structures of $\mathrm{Li}_{12}$ and $\mathrm{Li}_{19}$ are about 15-30 a.u. higher above the polarizabilities $\left(\alpha_{0}\right)$ obtained in the gas-phase calculations for optimized structures based on all the five simulation methods including CCSD theory. The corresponding standard deviation $\delta$ is around 30 a.u. for each DFT method, and around 20 a. u. for the CCSD level of theory. For $\mathrm{Li}_{6}$, the averaged simulated value is about 30 a.u. higher and the standard deviation is less than 20 a.u. for all these five levels of theories. For $\mathrm{Li}_{12}$, the CCSD simulated polarizability is within the range of experimental value. $\mathrm{For}_{\mathrm{Li}}$, the gap between the averaged polarizability and experimental error is within $\sim 50$ a.u. of threshold. All the coordinates for the GM clusters $\mathrm{Li}_{n}$, with $\mathrm{n}=2-20$ and the correspondingly bond-length distributions for $\mathrm{n}=11-20$ are provided in the supplementary material [28]. Statistical analyses based on the data sets from the longer trajectories $(\sim 10 \mathrm{ps})$ shows no improvement compared with the shorter trajectories, which is presented in the supplementary material [50]. This is not surprising as these clusters are small. 


\section{Conclusions}

In this work, we have systematically studied the global minima and polarizabilities of lithium clusters $\mathrm{Li}_{n}(n=1-20)$ with DFT and CC methods. We have used an improved basis-hopping based search algorithm to locate the global minima. Our calculations show that the CCSD results are closest to the experimental ones, the DFT results based on different exchange-correlation functional are consistent with each other and in overall good agreement with the measured data too. We have also studied the thermal fluctuation effects on the simulated polarizabilities via AIMD sampling at $300 \mathrm{~K}$ for the $\mathrm{Li}_{6}, \mathrm{Li}_{12}$ and $\mathrm{Li}_{19}$ clusters. As has been discussed above, thermal effects cannot account for the significant discrepancies between calculated and measured data for these clusters. For the largest cluster considered here ( $\left.\mathrm{Li}_{20}\right)$, we have demonstrated that proper determination of the cluster geometry plays a pivotal role in obtaining quantitative agreement with the experimental data. We also report a linear correlation (coefficient 0.996 ) for the inverse relationship between the CCSD calculated polarizability and IP for the $\mathrm{Li}_{n}$ clusters, which further strengthens our simulations. The measured polarizabilities of $\mathrm{Li}_{3}$ at various levels of theories including CCSDT, is still below the linear fitted line, which calls into question about the discrepancy of the polarizability for $\mathrm{Li}_{3}$.

\section{Acknowledgements}

H.S.H acknowledges Dr. Patrick Z. El-Khoury for helpful discussion. This work was supported by the Extreme Scale Computing Initiative (H.S.H., K.K.), a Laboratory Directed Research and Development Program at Pacific Northwest National Laboratory. Part of the calculations have been performed using EMSL, a national scientific user facility sponsored by the Department of Energy' s Office of Biological and Environmental Research and located at Pacific Northwest National Laboratory. The Pacific Northwest National Laboratory is operated for the U.S. Department of Energy by the Battelle Memorial Institute under Contract No. DE-AC06-76RLO-1830. Part of the calculations have been performed using Tsinghua National Laboratory for 
Information Science and Technology. Y. F. Zhao and J. L. were supported by NSF of China (NSFC grant Nos. 21433005 and 21221062).

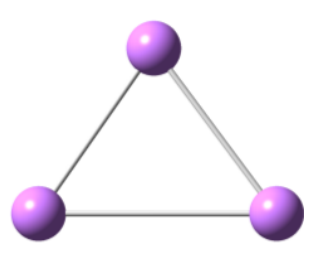

$\mathrm{Li}_{3}-\mathrm{C}_{2 \mathrm{v}}(a)$

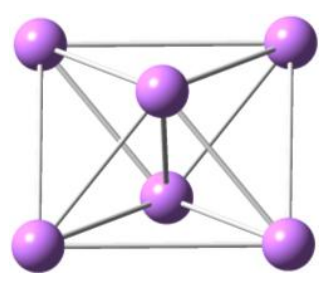

$\mathrm{Li}_{6}-\mathrm{D}_{4 \mathrm{~h}}$



$\mathrm{Li}_{7}-\mathrm{D}_{5 \mathrm{~h}}$

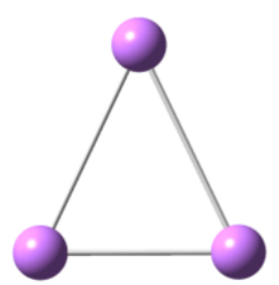

$\mathrm{Li}_{3}-\mathrm{C}_{2 \mathrm{v}}(b)$

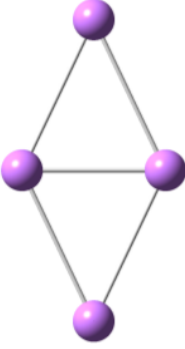

$\mathrm{Li}_{4}-\mathrm{D}_{4 \mathrm{~h}}$

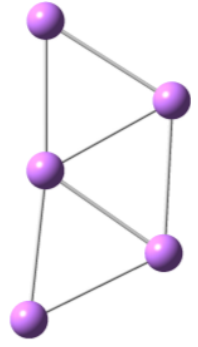

$\mathrm{Li}_{5}-\mathrm{C}_{2 \mathrm{v}}$

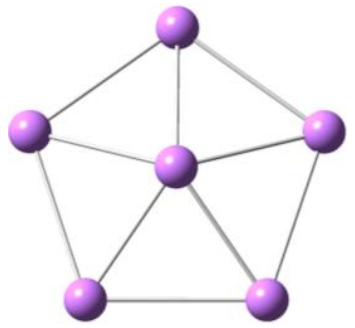

$\mathrm{Li}_{6}-\mathrm{C}_{5 \mathrm{v}}$

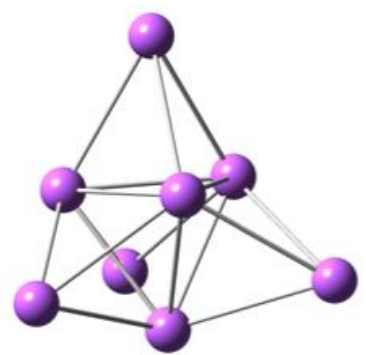

$\mathrm{Li}_{8}-\mathrm{T}_{\mathrm{d}}$

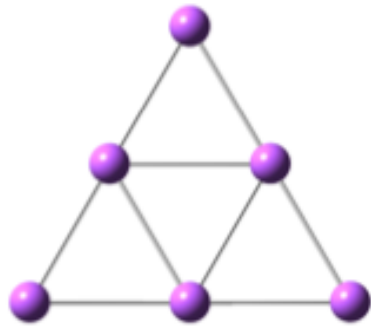

$\mathrm{Li}_{6}-\mathrm{C}_{5 \mathrm{v}}$

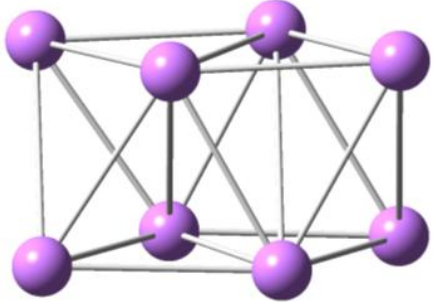

$\mathrm{Li}_{8}-\mathrm{C}_{1}$

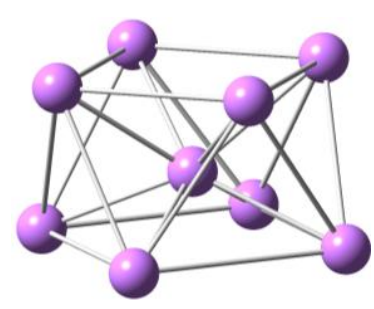

Lig- $\mathrm{C}_{1}$

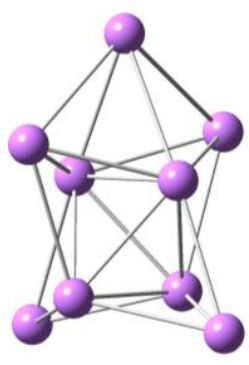

$\mathrm{Lig}-\mathrm{C}_{2 \mathrm{v}}$

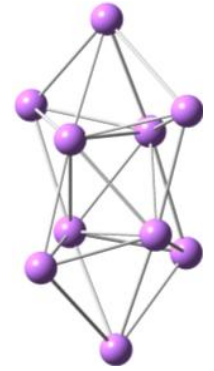

$\mathrm{Li}_{10}-\mathrm{D}_{2 \mathrm{~d}}$

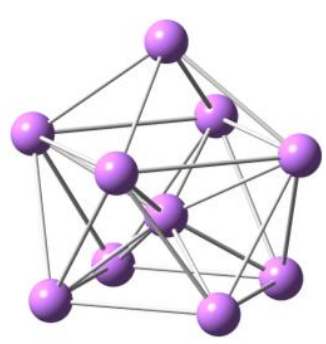

$\mathrm{Li}_{10}-\mathrm{C}_{4 \mathrm{v}}$ 
Fig. 1. The geometries of Li3-10 clusters including the global minima and isomers
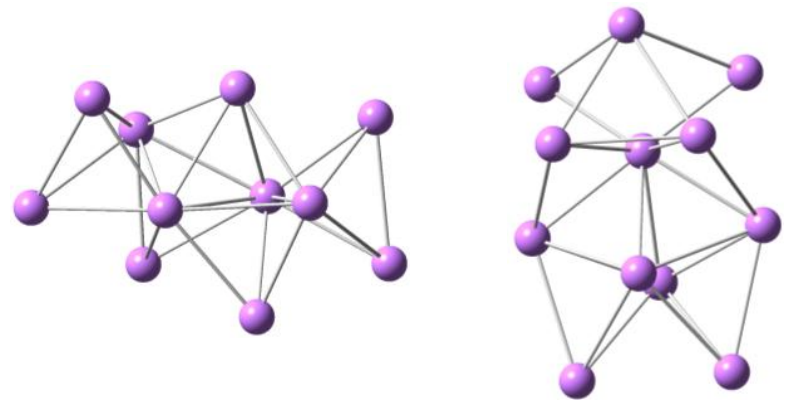

$\mathrm{Li}_{11}-\mathrm{C}_{2}$

$\mathrm{Li}_{12}-\mathrm{C}_{\mathrm{s}}$

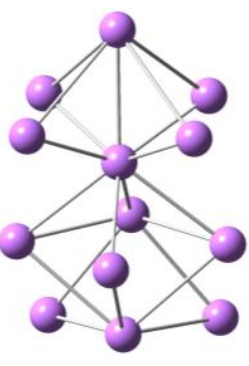

$\mathrm{Li}_{13}-\mathrm{C}_{\mathrm{S}}$

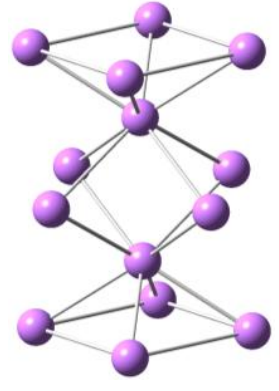

$\mathrm{Li}_{14}-\mathrm{D}_{4 \mathrm{~h}}$

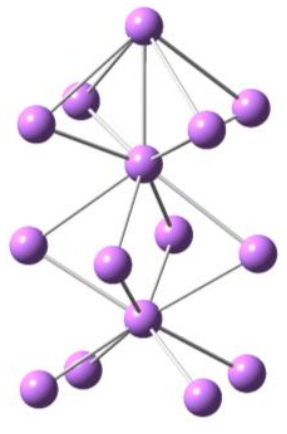

$\mathrm{Li}_{15}-\mathrm{C}_{2 \mathrm{v}}$

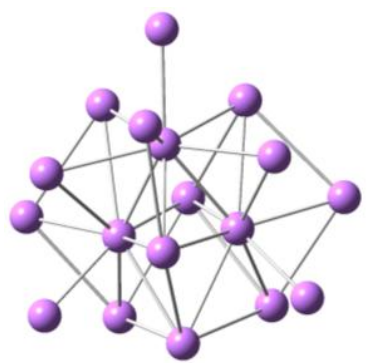

$\mathrm{Li}_{18}-\mathrm{C}_{1}$

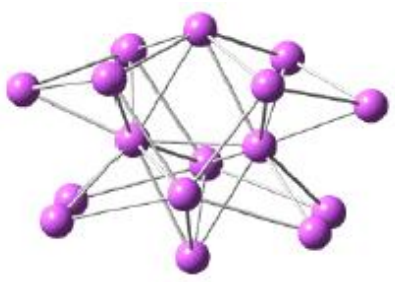

$\mathrm{Li}_{16}-\mathrm{C}_{2 \mathrm{v}}$

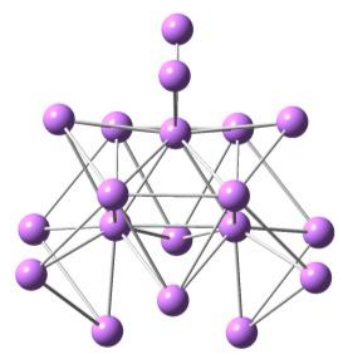

$\mathrm{Li}_{19}-\mathrm{C}_{2 \mathrm{v}}$

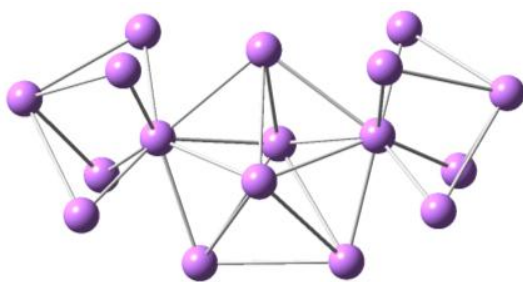

$\mathrm{Li}_{17}-\mathrm{C}_{2 \mathrm{v}}$



$\mathrm{Li}_{20}-\mathrm{C}_{1}$

Fig. 2. The geometries of $\mathrm{Li}_{11-20}$ clusters (the schematic connection for $\mathrm{Li}-\mathrm{Li}$ bond length $>3.0 \AA$ are omitted) 


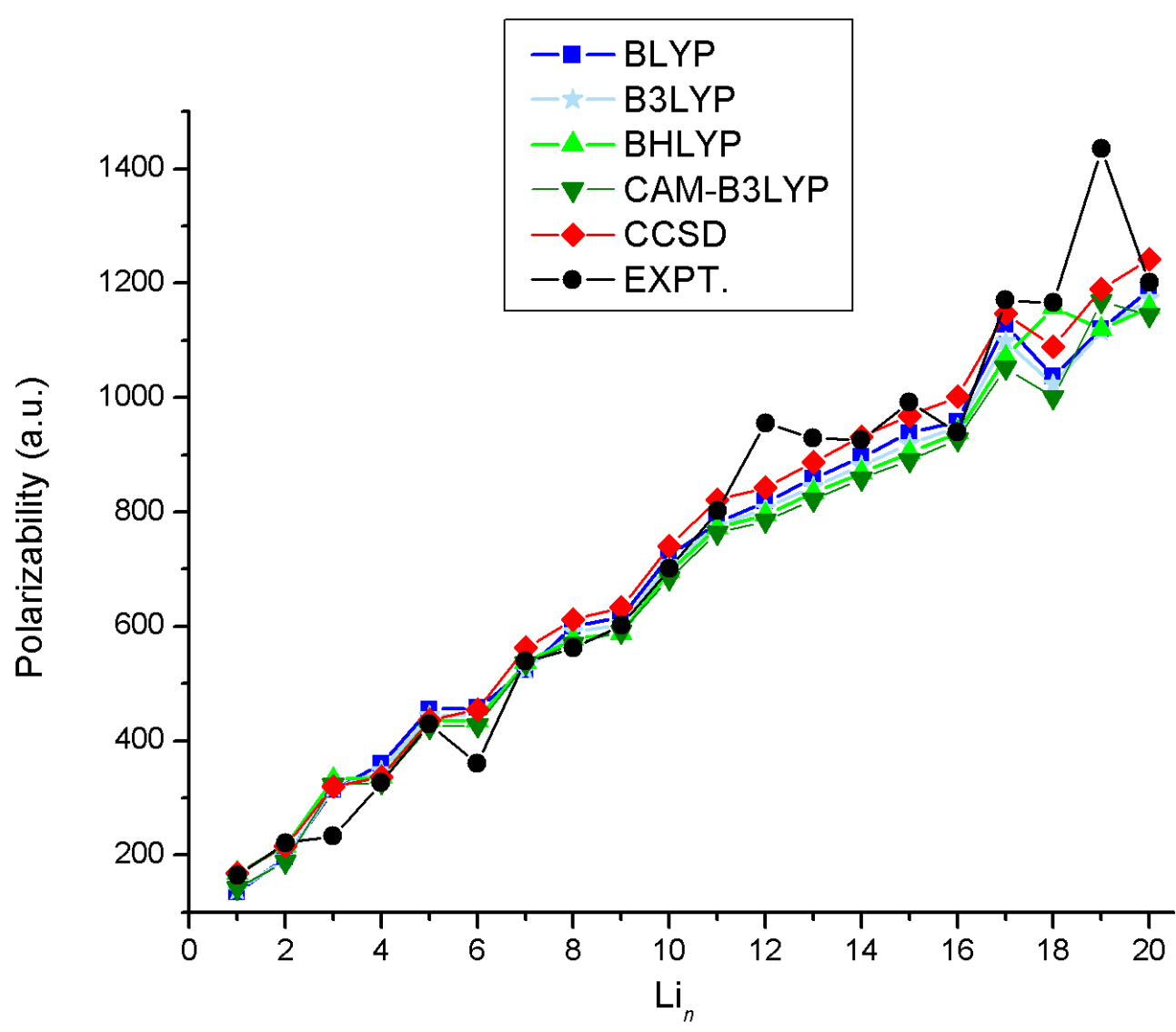

Fig. 3. The comparison of CCSD and DFT simulated and experimental polarizabilities for $\mathrm{Li}_{1}-\mathrm{Li}_{10}$ clusters. Color codes: black (experimental), red (CCSD), blue (BLYP), light blue (B3LYP), light green (BHLYP), dark green (CAM-B3LYP). 


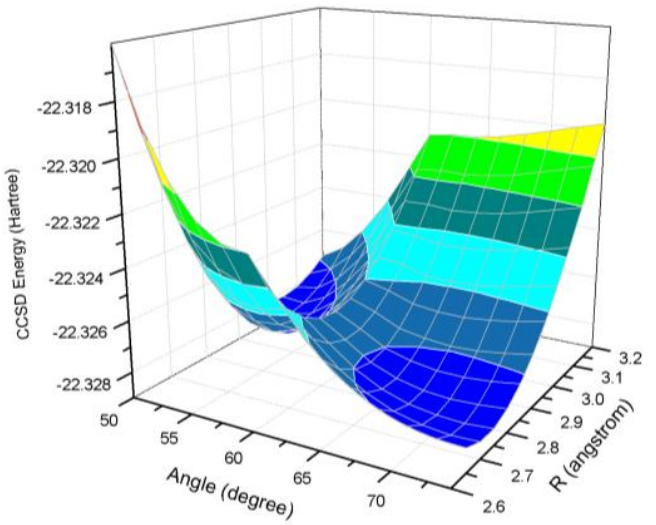

(a)



(b)

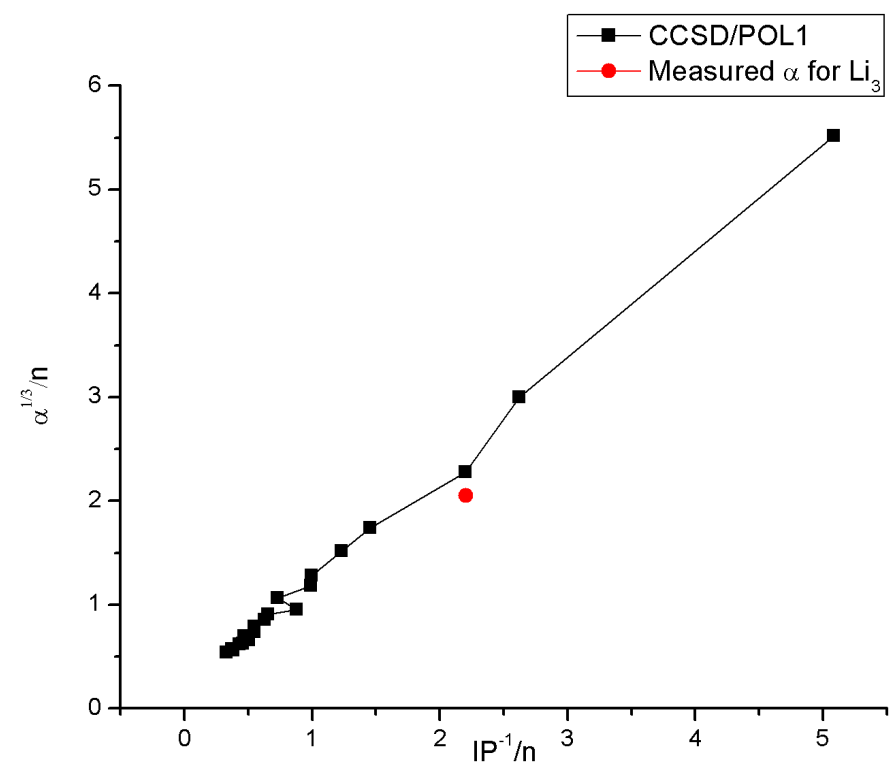

(c)

Fig. 4. The potential energy and polarizability surfaces of $\mathrm{Li}_{3}$ performed via CCSD/POL1 calculations: (a) the potential energy scan surface; (b) the polarizability scan surface. R here represents the equal length of Li-Li bond length of the isosceles triangle $\mathrm{Li}_{3}$. Angle here is the one formed between these two equal Li-Li bonds. (c) The relationship between the polarizability $(\alpha)$ and ionization potential (IP) of the lithium cluster $\mathrm{Li}_{n}$. There are two dots corresponding to $\mathrm{Li}_{3}$ : the black dot represents the calculated $\alpha$ while the red dot represents measured $\alpha$. All IP values are calculated at CCSD/POL1 level of theory. $\alpha$ and IP values are in atomic units and the factor " $n$ " refers to the number of 
atoms presents in the cluster. The linear fitting parameter is 0.99596 .

Table 1. The comparison between the experimental and calculated CCSD \& DFT isotropic polarizabilities (in a.u.) of $\mathrm{Li}_{n}$ clusters $(\mathrm{n}=1-20)$.

\begin{tabular}{|c|c|c|c|c|c|c|}
\hline${ }^{\mathrm{a}} \mathrm{Li}_{n}$ & BLYP & B3LYP & BHLYP & CAM-B3LYP & CCSD & Expt.c \\
\hline $\mathrm{Li}_{1}$ & 135.19 & 138.60 & 143.26 & 142.31 & 167.71 & $163.87 \pm 16$ \\
\hline $\mathrm{Li}_{2}$ & 196.31 & 194.15 & 190.82 & 188.12 & 216.00 & $221.35 \pm 22$ \\
\hline $\mathrm{Li}_{3}$ & 313.98 & 317.38 & 325.54 & 322.70 & 315.15 & $232.82 \pm 23$ \\
\hline $\mathrm{Li}_{4}$ & 358.98 & 347.39 & 335.49 & 327.65 & 338.00 & $326.62 \pm 33$ \\
\hline $\mathrm{Li}_{5}$ & 454.92 & 443.52 & 431.46 & 423.98 & 435.71 & $428.52 \pm 43$ \\
\hline $\mathrm{Li}_{6}$ & 456.96 & 445.62 & 435.06 & 426.72 & 453.67 & $360.36 \pm 36$ \\
\hline $\mathrm{Li}_{7}$ & 523.73 & 523.74 & 536.65 & 535.50 & 562.85 & $538.52 \pm 54$ \\
\hline $\mathrm{Li}_{8}$ & 600.26 & 590.09 & 578.37 & 569.34 & 611.83 & $561.47 \pm 56$ \\
\hline $\mathrm{Li}_{9}$ & 615.60 & 603.62 & 588.20 & 591.01 & 633.81 & $601.28 \pm 60$ \\
\hline $\mathrm{Li}_{10}$ & $723.72^{*}$ & $710.21^{*}$ & $695.58^{*}$ & $683.77^{*}$ & 740.50 & $701.83 \pm 70$ \\
\hline $\mathrm{Li}_{11}$ & 781.27 & 774.88 & 772.61 & 763.48 & 821.06 & $801.70 \pm 80$ \\
\hline $\mathrm{Li}_{12}$ & $818.33^{*}$ & $806.42^{*}$ & 795.73* & $784.35^{*}$ & 843.16 & $955.57 \pm 96$ \\
\hline $\mathrm{Li}_{13}$ & 858.20 & 844.73 & 833.63 & 822.15 & 887.59 & $929.92 \pm 93$ \\
\hline $\mathrm{Li}_{14}$ & 896.07* & 881.01* & 869.30* & $858.44^{*}$ & 931.52 & $925.87 \pm 93$ \\
\hline $\mathrm{Li}_{15}$ & 937.73 & 919.34 & 903.36 & 890.30 & 968.51 & $992.01 \pm 99$ \\
\hline $\mathrm{Li}_{16}$ & $958.09 *$ & $947.07^{*}$ & 939.03* & $927.53^{*}$ & 1001.71 & $939.37 \pm 94$ \\
\hline $\mathrm{Li}_{17}$ & 1126.64 & 1098.31 & 1071.09 & 1052.30 & 1146.56 & $1170.16 \pm 117$ \\
\hline $\mathrm{Li}_{18}$ & $1037.64^{*}$ & $1023.51^{*}$ & $1158.48^{*}$ & $1000.06^{*}$ & 1089.41 & $1166.11 \pm 117$ \\
\hline $\mathrm{Li}_{19}$ & 1120.07 & 1115.36 & 1119.58 & 1168.96 & 1190.54 & $1436.05 \pm 144$ \\
\hline $\mathrm{Li}_{20}$ & $1189.02^{*}$ & $1173.80^{*}$ & $1158.42^{*}$ & $1144.05^{*}$ & 1241.74 & $1201.21 \pm 120$ \\
\hline${ }^{\mathrm{b}} \delta$ & 91.79 & 95.98 & 93.46 & 96.97 & 74.05 & / \\
\hline
\end{tabular}

a All calculated isotropic polarizabilities (except the ones marked by “*”) are obtained by POL1 basis set at the B3LYP/cc-pVTZ optimized geometries on the basis of global-minimum searched structures. b The $\delta$ is the standard deviation of isotropic polarizabilities between the simulated value and the measured one.

c Ref. 11 
* cc-pVTZ basis set is used due to convergence problem in calculating the isotropic polarizability.

Table 2. The optimized B3LYP energy, single point CCSD(T) energy, and CCSD simulated isotropic polarizabilities of $\mathrm{Li}_{6}, \mathrm{Li}_{8}, \mathrm{Li} 9$ and $\mathrm{Li}_{10}$ isomers.

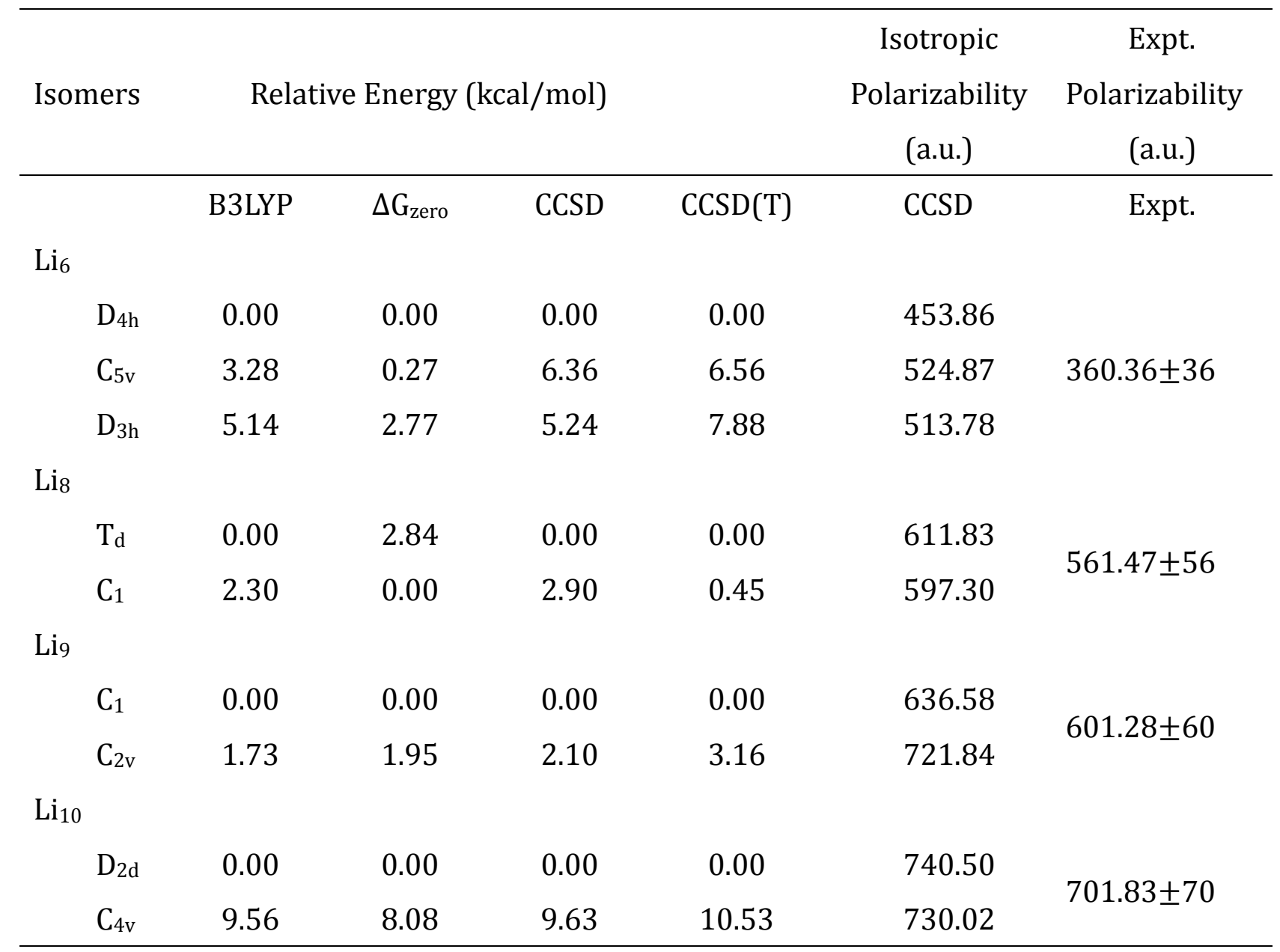


Table 3. CCSD simulated polarizabilities (in a.u.) of two $\mathrm{Li}_{3}$ isomers based on different basis sets of the $a$ and $b$ geometries obtained from CCSDT/POL1 optimization

\begin{tabular}{cccccc}
\hline & POL1 & aug-cc-pVDZ & aug-cc-pVTZ & aug-cc-pVQZ & cc-pV5Z \\
\hline $\mathrm{Li}_{3}(a)$ & 323.70 & 323.86 & 326.76 & 325.88 & 323.36 \\
$\mathrm{Li}_{3}(b)$ & 315.15 & 314.59 & 318.02 & 317.04 & 314.17 \\
Num. Basis & 72 & 69 & 138 & 240 & 273 \\
\hline
\end{tabular}

$\left(R_{a}=2.736 \AA, \theta_{a}=71.23^{\circ} ; R_{b}=2.983 \AA, \theta_{b}=52.49^{\circ}\right)$

Table 4. CCSDT/POL1 simulated polarizabilities (in a.u.) of small clusters Li 1-4 $_{1}$ and the $\mathrm{a}$ and $\mathrm{b}$ geometries of $\mathrm{Li}_{3}$ are obtained from CCSDT/POL1 optimization

\begin{tabular}{cccccc}
\hline & & & & & \\
& $\mathrm{Li}_{1}$ & $\mathrm{Li}_{2}$ & $\mathrm{Li}_{3}(a)$ & $\mathrm{Li}_{3}(b)$ & $\mathrm{Li}_{4}$ \\
\hline$\alpha$ & 167.72 & 214.92 & 315.85 & 315.27 & 344.94 \\
Expt. $\alpha$ & $163.87 \pm 16$ & $221.35 \pm 22$ & $232.82 \pm 23$ & $326.62 \pm 33$ \\
\hline
\end{tabular}


Table 5. The statistical analysis of the isotropic polarizabilities computed from 50 randomly selected geometries of $\mathrm{Li}_{6}, \mathrm{Li}_{12}$, and $\mathrm{Li}_{19}$ at both DFT and CCSD levels of theory.

\begin{tabular}{|c|c|c|c|c|c|c|}
\hline & BLYP & B3LYP & BHLYP & CAM1 & ${ }^{\mathrm{d}} \mathrm{CCSD}$ & Expt. \\
\hline \multicolumn{7}{|l|}{$\mathrm{Li}_{6}$} \\
\hline${ }^{\text {a }} \alpha_{0}$ & 456.96 & 445.62 & 435.06 & 426.72 & 453.67 & \multirow{3}{*}{$360.36 \pm 36$} \\
\hline $\mathrm{b}\langle\alpha\rangle$ & 486.92 & 476.24 & 465.96 & 456.75 & 485.86 & \\
\hline${ }^{\mathrm{c}} \delta$ & 16.09 & 16.21 & 16.14 & 18.25 & 17.17 & \\
\hline \multicolumn{7}{|l|}{$\mathrm{Li}_{12}$} \\
\hline а $\alpha_{0}$ & 818.33* & $806.42^{*}$ & 795.73* & $784.35^{*}$ & 843.16 & \multirow{3}{*}{$955.57 \pm 96$} \\
\hline $\mathrm{b}\langle\alpha\rangle$ & $844.75^{*}$ & $831.65^{*}$ & 819.60* & $807.70^{*}$ & 860.98 & \\
\hline${ }^{\mathrm{c}} \delta$ & $30.32^{*}$ & $29.22^{*}$ & $27.94^{*}$ & $27.54^{*}$ & 23.26 & \\
\hline \multicolumn{7}{|l|}{$\mathrm{Li}_{19}$} \\
\hline${ }^{\mathrm{a}} \alpha_{0}$ & 1120.07 & 1115.36 & 1119.58 & 1168.96 & 1190.54 & \multirow{3}{*}{$1436.05 \pm 144$} \\
\hline $\mathrm{b}\langle\alpha\rangle$ & 1152.15 & 1147.62 & 1147.85 & 1202.82 & 1224.36 & \\
\hline${ }^{c} \delta$ & 31.89 & 31.51 & 32.05 & 32.84 & 23.34 & \\
\hline
\end{tabular}

a $\alpha_{0}$ is the computed isotropic polarizability of $\mathrm{Li}_{6}, \mathrm{Li}_{12}$ and $\mathrm{Li}_{19}$ at the B3LYP/cc-pVTZ optimized geometries using DFT and CCSD levels of theory, respectively.

${ }^{b}\langle\alpha\rangle$ is the mean value of isotropic polarizability on the basis of 50 randomly selected geometries $\left(\alpha_{i, i=1-50}\right)$ generated from AIMD: $\langle\alpha\rangle=\frac{1}{50} \sum_{i=1}^{50} \alpha_{i}$

c $\delta$ is the standard deviation: $\delta=\sqrt[2]{\frac{1}{50} \sum_{i=1}^{50}\left(\alpha_{i}-\langle\alpha\rangle\right)^{2}}$

${ }^{d}$ Here 18 (for $\mathrm{Li}_{12}$ ) and 14 (for $\mathrm{Li}_{19}$ ) randomly selected geometries were used for expensive CCSD calculations.

* cc-pVTZ basis set is used here instead of POL1 due to convergence issue. 
Table 6. The computed IP of lithium clusters based on two types of methods. IP-DD-CCSD represents the vertical IP from the direct differences between CCSD calculated energies for neutral and cation lithium clusters. IP-EOM-CCSD represents the vertical IP from EOM-CCSD calculation.

\begin{tabular}{ccc}
\hline Clusters & IP-DD-CCSD $(\mathrm{eV})$ & IP-EOM-CCSD $(\mathrm{eV})$ \\
\hline $\mathrm{Li}_{1}$ & 5.35 & $/$ \\
$\mathrm{Li}_{2}$ & 5.19 & 5.2 \\
$\mathrm{Li}_{3}$ & 4.12 & $/$ \\
$\mathrm{Li}_{4}$ & 4.67 & 4.72 \\
$\mathrm{Li}_{5}$ & 4.42 & $/$ \\
$\mathrm{Li}_{6}$ & 4.56 & 4.66 \\
$\mathrm{Li}_{7}$ & 3.92 & $/$ \\
$\mathrm{Li}_{8}$ & 4.67 & 4.75 \\
$\mathrm{Li}_{9}$ & 3.44 & $/$ \\
$\mathrm{Li}_{10}$ & 4.16 & 4.24 \\
$\mathrm{Li}_{11}$ & 3.93 & $/$ \\
$\mathrm{Li}_{12}$ & 4.12 & 4.2 \\
$\mathrm{Li}_{13}$ & 3.8 & $/$ \\
$\mathrm{Li}_{14}$ & 4.15 & 4.21 \\
$\mathrm{Li}_{15}$ & 3.58 & $/$ \\
$\mathrm{Li}_{16}$ & 3.69 & 3.77 \\
$\mathrm{Li}_{17}$ & 3.71 & $/$ \\
$\mathrm{Li}_{18}$ & 4.08 & 4.16 \\
$\mathrm{Li}_{19}$ & 3.73 & $/$ \\
$\mathrm{Li}_{20}$ & 4.1 & \\
& & \\
\hline
\end{tabular}




\section{Reference:}

[1] A.D. Quint̃aoa, R.O. Vianna, J.R. Mohallem, Eur. Phys. J. D 6 (1999) 89.

[2] S.P. de Visser, D. Danovich, S. Shaik, Phys. Chem. Chem. Phys. 5 (2003) 158.

[3] P. Fantucci, V. Bonacic-Koutecky, J. Jellinek, M. Wiechert, R.J. Harrison, M.F. Guest, Chem. Phys. Lett. 250 (1996) 47.

[4] E. Benichou, R. Antoine, D. Rayane, B. Vezin, F.W. Dalby, P. Dugourd, M. Broyer, C. Ristori, F.

Chandezon, B.A. Huber, J.C. Rocco, S.A. Blundell, C. Guet, Phys. Rev. A 59 (1999) R1.

[5] P. Dugourd, D. Rayane, P. Labastie, B. Vezin, J. Chevaleyre, M. Broyer, Chem. Phys. Lett. 197 (1992) 433.

[6] A.N. Alexandrova, A.I. Boldyrev, X. Li, H.W. Sarkas, J.H. Hendricks, S.T. Arnold, K.H. Bowen, J. Chem. Phys. 134 (2011) 044322.

[7] M.E. Alikhani, S. Shaik, Theor. Chem. Acc. 116 (2006) 390.

[8] R. Fournier, J.B.Y. Cheng, A. Wong, J. Chem. Phys. 119 (2003) 9444.

[9] F.D. Sala, R. Rousseau, A. Görling, D. Marx, Phys. Rev. Lett. 92 (2004) 183401.

[10] M.E. Alikhani, S. Shaik, Theor. Chem. Acc. 116 (2006) 390.

[11] R. Rousseau, D. Marx, J. Chem. Phys. 111 (1999) 5091.

[12] L. Jensen, J. Autschbach, G.C. Schatz, J. Chem. Phys. 122 (2005) 224115.

[13] P. Dugourd, J. Blanc, V. Bonacic-Koutecky, M. Broyer, J. Chevaleyre, J. Koutecky, J. Pittner, J. Wolf, L. Wöste, Phys. Rev. Lett. 67 (1991) 2638.

[14] D. Reichardt, V. Bonačić-Koutecký, P. Fantucci, J. Jellinek, Chem. Phys. Lett. 279 (1997) 129.

[15] R. Rousseau, D. Marx, Phys. Rev. Lett. 80 (1998).

[16] G.D. Purvis, R.J. Bartlett, J. Chem. Phys. 76 (1982) 1910.

[17] K. Raghavachari, G.W. Trucks, J.A. Pople, M. Head-Gordon, Chem. Phys. Lett. 157 (1989) 479.

[18] K.R.S. Chandrakumar, T.K. Ghanty, S.K. Ghosh, Int. J. Quantum Chem. 105 (2005) 166.

[19]J.R. Hammond, K. Kowalski, W.A. deJong, J. Chem. Phys. 127 (2007) 144105.

[20]T. Helgaker, S. Coriani, P. Jorgensen, K. Kristensen, J. Olsen, K. Ruud, Chem. Rev. 112 (2012) 543.

[21] D.J. Wales, J.P.K. Doye, J. Phys. Chem. A 101 (1997) 5111.

[22] (a) H.J. Zhai, Y.F. Zhao, W.L. Li, Q. Chen, H. Bai, H.S. Hu, Z.A. Piazza, W.J. Tian, H.G. Lu, Y.B. Wu, Y.W. Mu, G.F. Wei, Z.P. Liu, J. Li, S.D. Li, L.S. Wang, Nat. Chem. 6 (2014) 727.

[23] W.G. Richards, P.J. Ballester, Proc. R. Soc. Lond. A, Math. Phys. Eng. Sci. 463 (2007) 1307.

[24] P. Pyykkö, M. Atsumi, Chem. Eur. J. 15 (2009) 186.

[25] J.P. Perdew, K. Burke, M. Ernzerhof, Phys. Rev. Lett. 77 (1996) 3865.

[26] T.H. Dunning, J. Chem. Phys. 53 (1970) 2823.

[27] A. D. Becke, J. Chem. Phys. 98 (1993) 5648.

[28] T. H. Dunning, J. Chem. Phys. 90 (1989) 1007.

[29] J. R. Hammond, N. Govind, K. Kowalski, J. Autschbach, S. S. Xantheas, J. Chem. Phys. 131 (2009)

214103.

[30] M. Valiev, E. J. Bylaska, N. Govind, K. Kowalski, T. P. Straatsma, H. J. J. van Dam, D. Wang, J.

Nieplocha, E. Apra, T.L. Windus, W.A. de Jong, Comput. Phys. Commun. 181 (2010) 1477.

[31] C. Lee, W. T. Yang, R. G. Parr, Phys. Rev. B 37 (1988) 785.

[32] A. D. Becke, J. Chem. Phys. 98 (1993) 1372.

[33] T. Yanai, D. P. Tew, N. C. Handy, Chem. Phys. Lett. 393 (2004) 51.

[34] A. J. Sadlej, M. Urban, J. Mol. Struct.-Theochem 234 (1991) 147.

[35] H.S. Hu, K. Bhaskaran-Nair, E. Apra, N. Govind, K. Kowalski, J. Phys. Chem. A 118 (2014) 9087.

[36] Krämer, M. Keil, C.B. Suarez, W. Demtröder, W. Meyer, Chem. Phys. Lett. 299 (1999) 212.

[37] I.K. Dmitrieva, G.I. Plindov, Phys. Scripta 27 (1983) 402.

[38] K.R.S. Chandrakumar, T.K. Ghanty, S.K. Ghosh, J. Phys. Chem. A 108 (2004) 6661.

[39] A. Monari, J. Pitarch-Ruiz, G.L. Bendazzoli, S. Evangelisti, J. Sanchez-Marin, J. Chem. Theory 
Comput. 4 (2008) 404.

[40] G. Gardet, F. Rogemond, H. Chermette, J. Chem. Phys. 105 (1996) 9933.

[41] N. Goel, S. Gautam, K. Dharamvir, Int. J. Quantum Chem. 112 (2012) 575.

[42] B. Temelso, C.D. Sherrill, J. Chem. Phys. 122 (2005) 064315.

[43] H. J. Zhai, B. Kiran, B. Dai, J. Li, L.S. Wang, J. Am. Chem. Soc. 127 (2005) 12095.

[44] J.M. Pacheco, J.L. Martins, J. Chem. Phys. 106 (1997) 6039.

[45] J. Li, X. Li, H.J. Zhai, L.S. Wang, Science 299 (2003) 864.

[46] P.C. Hariharan, J.A. Pople, Theor. Chim. Acta 28 (1973) 213.

[47] W.C. Swope, H.C. Andersen, P.H. Berens, K.R. Wilson, J. Chem. Phys. 76 (1982) 637.

[48] G. Bussi, D. Donadio, M. Parrinello, J. Chem. Phys. 126 (2007) 014101.

[49] S.A. Fischer, T.W. Ueltschi, P.Z. El-Khoury, A.L. Mifflin, W.P.W. Hess, H. F. Wang , C.J. Cramer, N.

Govind, J. Phys. Chem. B, Article ASAP DOI: 10.1021/acs.jpcb.5b03323 (2015).

[50] See supplemental material at [URL will be inserted by AIP] for statistical analysis of the isotropic polarizabilities (Table S1), optimized geometry coordinates of $\mathrm{Li}_{n}(n=2-20)$ clusters (Section 2), bond length distributions for the $\mathrm{Li}_{n}(n=11-20)$ clusters (Figure S1-S10). [Supplementary Material] 


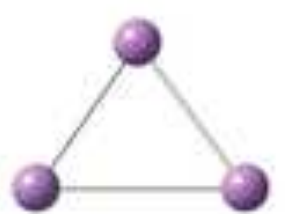

$\mathrm{LH}_{3}-\mathrm{C}_{2 \mathrm{v}}(a)$

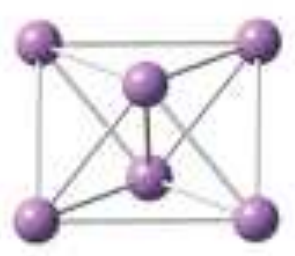

$\mathrm{L}_{6}$ - $\mathrm{D}_{4 \mathrm{~h}}$

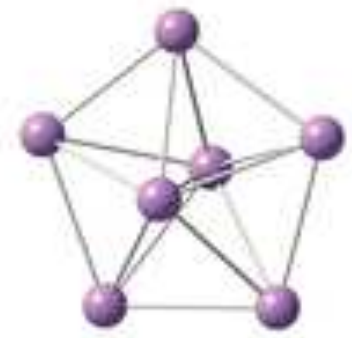

Liy-Dss

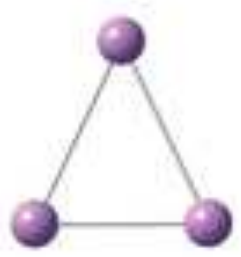

$\mathrm{L} . \mathrm{I}_{3} \cdot \mathrm{C}_{2 \mathrm{v}}(\mathrm{b})$

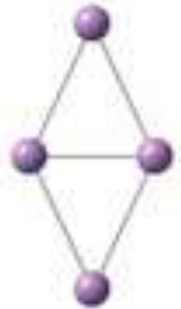

Lit $-D_{4 h}$

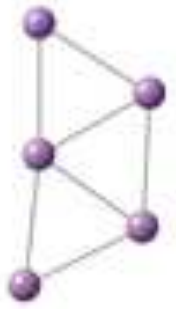

$\mathrm{Li}_{5}-\mathrm{C}_{2 \mathrm{v}}$

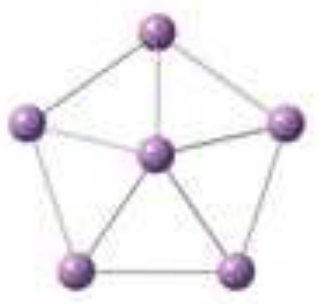

$\mathrm{Lit}_{6}-\mathrm{C}_{\text {Siv }}$

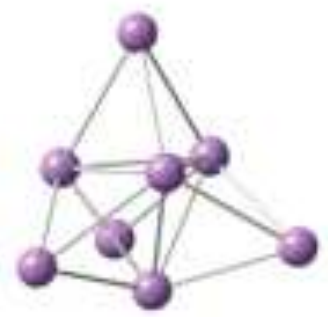

Lis $-T_{\text {a }}$

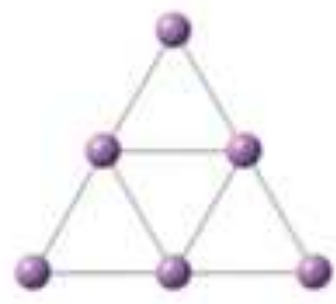

$\mathrm{Li}_{6}-\mathrm{C}_{5 \mathrm{v}}$

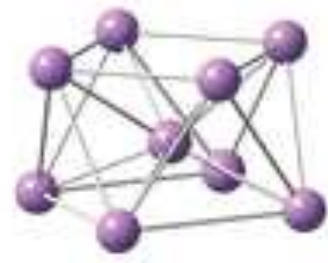

Lis- $\mathrm{C}_{1}$

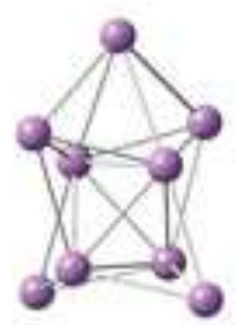

$\mathrm{Lig}-\mathrm{C}_{2 x}$

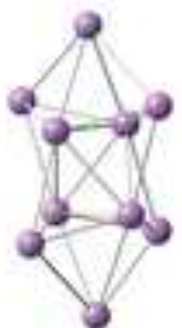

Liso- $D_{2 a}$

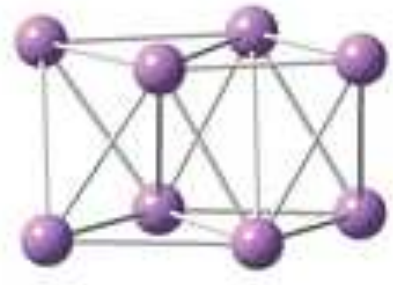

L.t. $-\mathrm{C}_{1}$

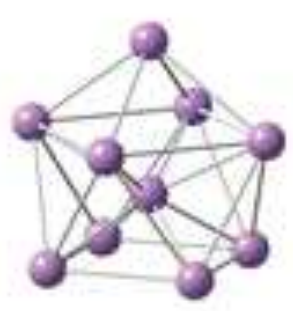

$\mathrm{Lij}_{1 \mathrm{u}}-\mathrm{C}_{\mathrm{Av}}$ 




$\mathrm{Li}_{12}-\mathrm{C}_{\mathrm{s}}$

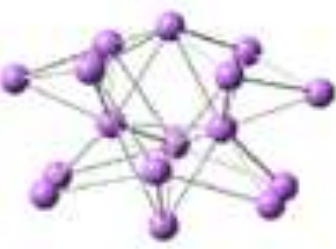

$\mathrm{Li}_{16} \cdot \mathrm{C}_{2 v}$

$\mathrm{Li}_{1} v-\mathrm{C}_{2 \mathrm{v}}$

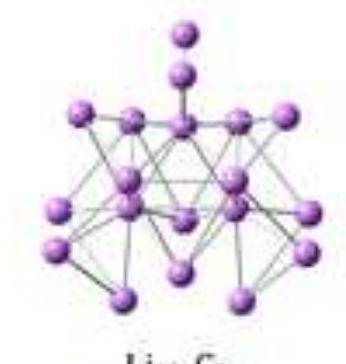

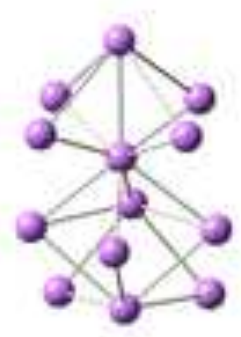

$\mathrm{Li}_{13} \cdot \mathrm{C}_{5}$

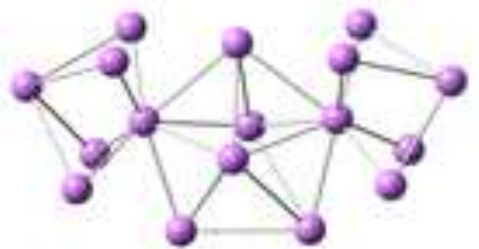

$\mathrm{Li}_{17}-\mathrm{C}_{2 v}$

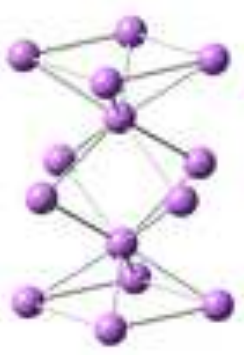

$\mathrm{Li}_{14}-\mathrm{D}_{\text {fh }}$

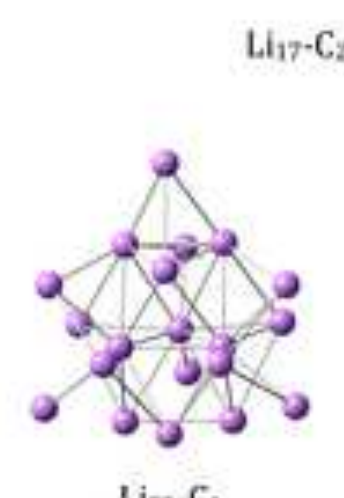

$\mathrm{Li}_{20}-\mathrm{C}_{1}$

Cin
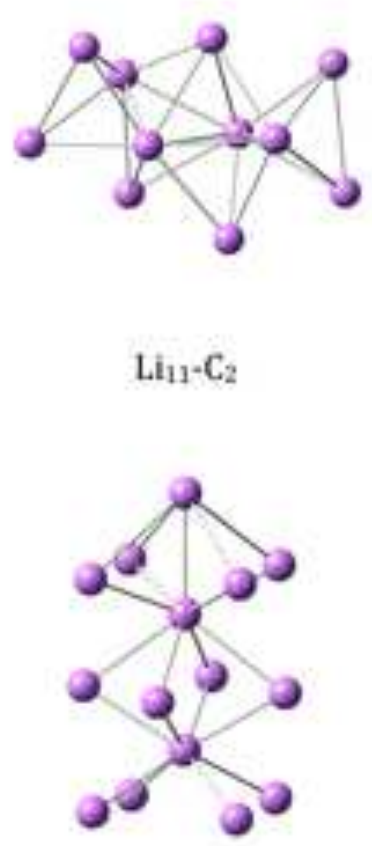

$\mathrm{Lit}_{15}-\mathrm{C}_{2 \mathrm{v}}$

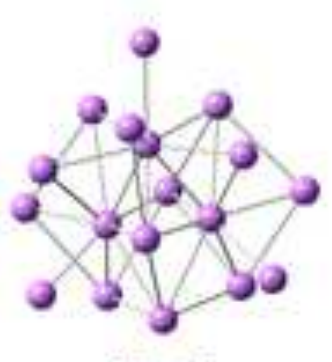

$\mathrm{Li}_{18}-\mathrm{C}_{1}$
2

, 


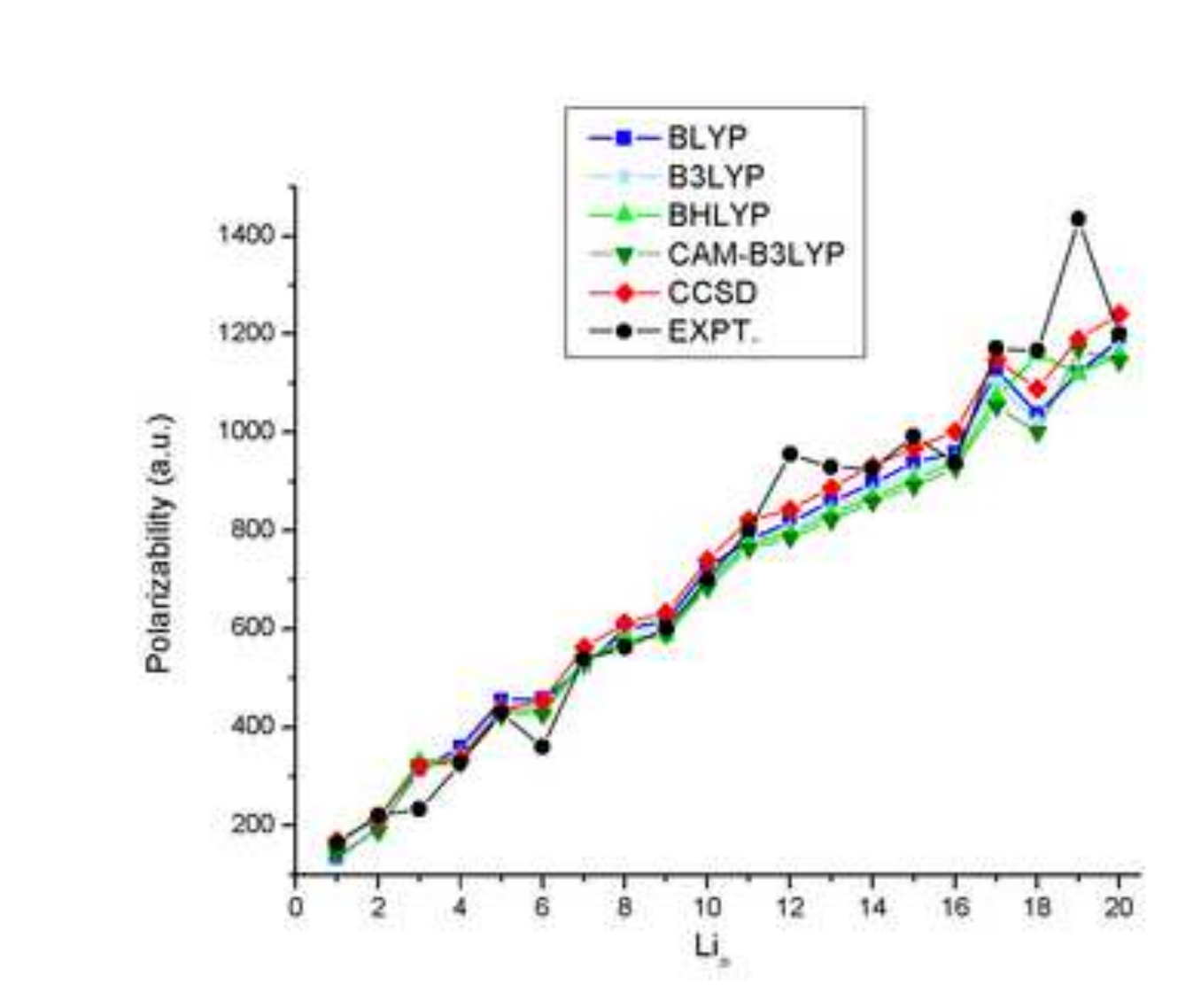

Figure

3

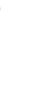

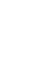

.

rat

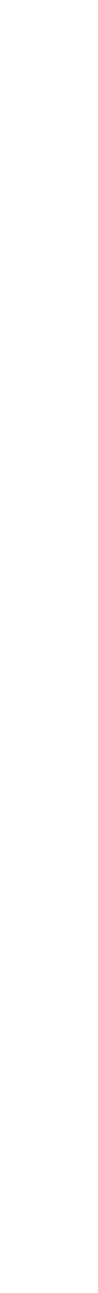




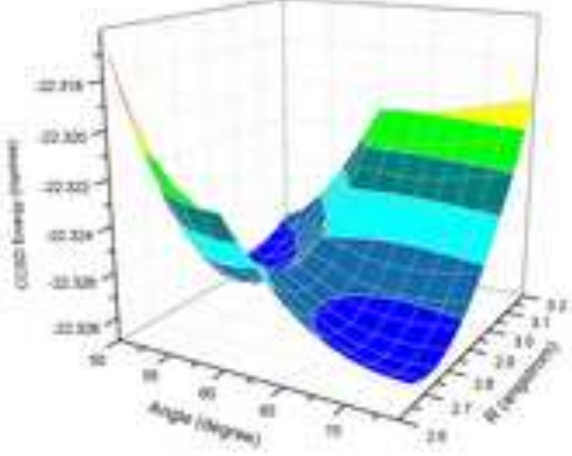

(a)

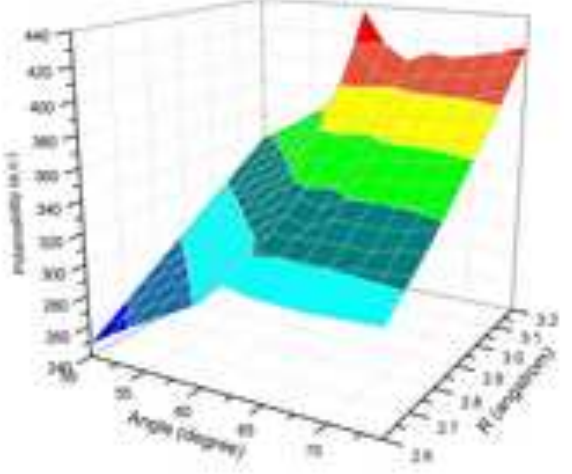

(b)

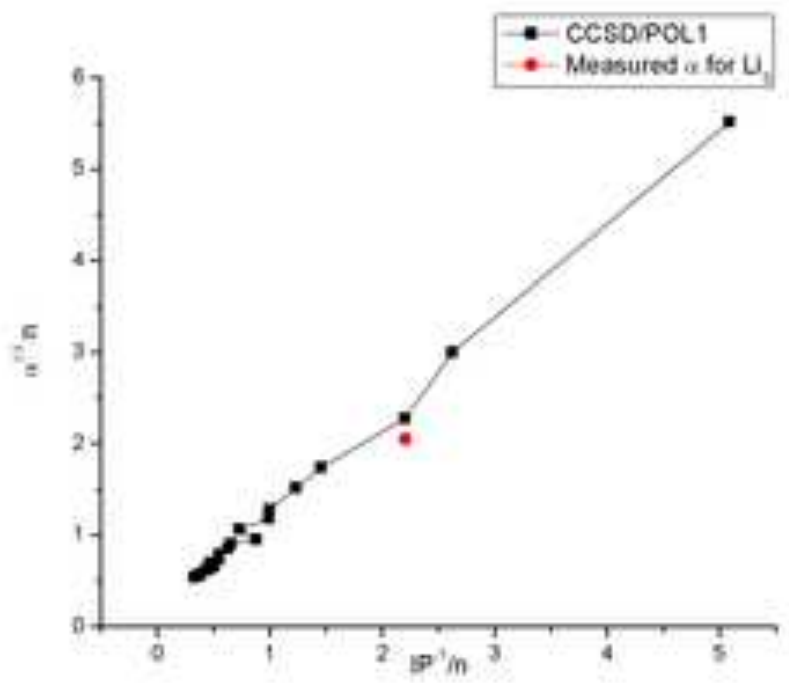

(c) 


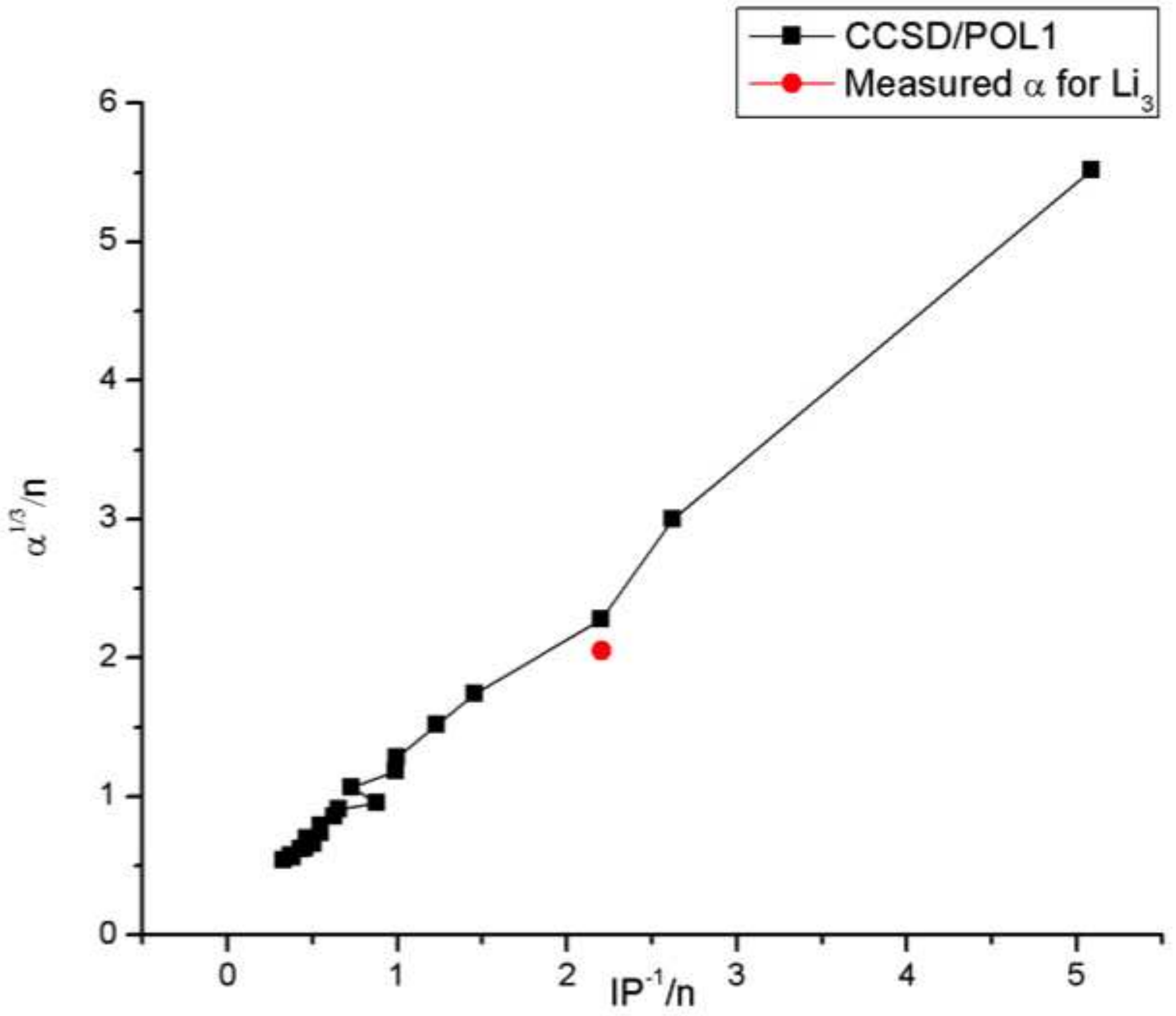

